Linguagem em (Dis)curso - LemD, v. 8, n. 3, p. 439-466, set./dez. 2008

\title{
CONSTRUÇÕES IDENTITÁRIAS: SER LEITOR E ALFABETIZADOR DE JOVENS E ADULTOS
}

Claudia Lemos Vóvio*

\begin{abstract}
Resumo: Este artigo focaliza as relações entre linguagem e construção de identidades leitoras por alfabetizadores de jovens e adultos. Apresenta resultados de uma pesquisa de doutorado que teve como foco o letramento desses agentes. Ao interpelar os discursos desses agentes sobre si mesmos e aceder aos sentidos atribuídos à leitura, pretende-se contribuir para $\mathrm{O}$ delineamento de processos de formação. A análise, numa perspectiva lingüístico-enunciativo-discursiva, revelou um aspecto distintivo frente aos resultados de pesquisas prévias com profissionais docentes: a forma assertiva e positivada com que produziram imagens de si, como leitores e, conseqüentemente, como alfabetizadores. Nessa construção, observa-se ainda um movimento de autolegitimação por meio de operações discursivas que têm como foco a exaltação de propriedades pessoais, a referência a objetos culturais tomados como legítimos e o trânsito por novas práticas culturais. Palavras-chave: identidade; letramento; prática de leitura; formação de professores; alfabetização de jovens e adultos.
\end{abstract}

\section{INTRODUÇÃO}

Este artigo apresenta resultados de pesquisa de doutorado (VÓVIO, 2007) ${ }^{1}$ enfocando um grupo de alfabetizadores de jovens e adultos, suas histórias e práticas de leitura, a partir de seus enunciados sobre como se concebem como leitores, que também indiciam papéis e posições sociais. As inquietações que se colocaram como motores dessa

\footnotetext{
*Professora da Unifesp. Doutora em Lingüística Aplicada. E-mail: <clvovio@uol.com.br>.

1 A pesquisa, finalizada em 2007, desenvolveu-se no âmbito do Projeto Temático FAPESP Letramento do Professor: processos de retextualização e práticas de letramento, sob a coordenação da Profa. Dra. Angela Kleiman, do Instituto de Estudos de Linguagem da Unicamp. Durante sua realização, a pesquisadora contou com bolsa FAPESP.
} 
investigação diziam respeito, de modo amplo, às necessidades formativas e de profissionalização de alfabetizadores que são convocados e $\operatorname{autorizados}^{2}$ a introduzir pessoas jovens e adultas na aprendizagem da leitura e a ampliar seu repertório de práticas sociais de uso da escrita. A problemática central são os modos de letramento desses agentes educativos, pertencentes a famílias com baixa escolaridade, em condição de vulnerabilidade social e com percursos irregulares de escolarização, engajados em práticas sociais que colocam sob suspeita fatores tomados como condicionantes em suas experiências de socialização no universo da escrita (KLEIMAN, 2005; LAHIRE 2002, 2006; RIBEIRO, 2005).

Durante três semestres, dez dos alfabetizadores que atuavam em um programa de alfabetização, Educar para Mudar, desenvolvido em Itaquaquecetuba (Região Metropolitana de São Paulo) ${ }^{3}$, tomaram parte de uma série de situações criadas para fins dessa pesquisa. As situações e os instrumentos utilizados na geração de dados possibilitaram, de modo dinâmico, situado e colaborativo, a produção de discursos, sua revisão e a reflexão sobre as apreciações dos participantes sobre a leitura e sobre suas identidades.

Neste artigo, apresenta-se a produção discursiva do grupo numa das rodas de conversa, sessões coletivas dirigidas. Nessa produção, foram produzidas e reveladas, nas interações, identidades compreendidas como circunstanciais e instáveis, à mercê das injunções da própria situação de produção do discurso e dos sistemas de significação sociais disponíveis (WOODWARD, 2000). Nos enunciados analisados, os participantes apropriaram-se das vozes sociais em jogo, atuando sobre elas de forma inventiva, no sentido de adequar seus dizeres ao contexto imediato da comunicação, produzindo outras significações. Portanto, as significações não se mostraram idênticas, nem tão estáveis. Sofreram

\footnotetext{
${ }^{2} \mathrm{Na}$ alfabetização de jovens e adultos, nas suas várias formas, é comum a convocação de educadores com níveis de escolarização, formação e estatuto profissional variados. Os programas organizados a partir da sociedade civil admitem educadores sem formação específica para a docência, mas com o ensino médio e experiência como agentes educativos.

3 O Projeto Educar para Mudar era desenvolvido, em parceria com o governo do Estado, pelo CECASI - Conselho de Educação Cultura e Ação Social de Itaquaquecetuba, que funciona como uma subsede da ONG Conselho Comunitário de Educação, Cultura e Ação Social da Grande São Paulo. No período da pesquisa, mantinha 49 turmas de alfabetização de jovens e adultos, contando com 49 educadores (a maior parte deles sem formação para a docência, com o ensino médio completo) e 5 coordenadores pedagógicos.
}

VÓVIO - Construções identitárias... 
injunções próprias da interação em curso, na qual alfabetizadores, diante da pesquisadora ${ }^{4}$, abordam temas referentes à leitura e, para tal, fizeram escolhas e seleções sobre o que e como dizer. Mais do que filiações explícitas a abordagens sobre a leitura, os enunciados mostraram-se como que em processo, híbridos, em confronto e mudança, à medida que novos temas foram introduzidos e que transcorreu o processo de produção de sentidos, em interação.

\section{OS DISCURSOS CORRENTES SOBRE A LEITURA: SIGNIFICAÇÕES EM JOGO}

Perguntar que leitor ou leitora se é pressupõe escolhas para autodefinir-se e objetivar-se como tal, para afirmar ou negar ser leitor ou para ser algo para além disso. Essas escolhas são circunscritas e relacionais, e derivadas da experiência no mundo social com e entre leituras, envolvendo os alfabetizadores-participantes em ações de (re)conhecimento e de exame de sistemas classificatórios (ser ou não leitor, ser um leitor-tipo), de símbolos que indiciam e configuram identificações e diferenciações com leitores, de significações sobre a leitura e o que se pode fazer com ela, de exercício e de tomada de consciência de papéis atribuídos e ocupados em práticas de leitura (o que cada um faz com os outros à medida que se dedica à leitura e como essa ação dialeticamente retorna a cada um deles), e de como as relações entre leitores e não leitores estão ordenadas.

Ao enunciarem que leitor ou leitora eles são, os alfabetizadoresparticipantes esparramaram na interação as significações que atribuíram às suas identidades, trouxeram vozes sociais ${ }^{5}$ de modo explícito ou

4 Antes da pesquisa, a pesquisadora atuara como formadora e assessora no Projeto Educar para Mudar, no âmbito da ONG Ação Educativa.

5 Por vozes sociais, conceito fundante dos estudos da linguagem do Círculo de Bakhtin, compreende-se a rede de significações sociais disponível e em (re)construção, a partir da qual se pode dizer e interpretar o mundo e a realidade. Essas interpretações e sentidos se mostram em consonância com a dinâmica da história e das experiências dos grupos sociais, de sua atividade no mundo, no qual, ao mesmo tempo em que são desenvolvidas, produzem valorações diversas que conotam a própria atividade, os objetos e relações sociais nela envolvidas. As palavras com as quais se diz o mundo "são tecidas a partir de uma multidão de fios ideológicos e servem de trama a todas as relações sociais em todos os domínios. É, portanto, claro que a palavra será sempre o 


\section{2}

implícito. Essas vozes e significações funcionaram como compostos para a produção de seus posicionamentos, identificações e diferenciações, replicaram outros já-ditos, disputaram posições frente às propriedades que podem confirmar a condição e a identidade declarada.

É a respeito desse jogo de posições que serão tecidas considerações sobre a leitura e o modo como vem sendo abordada nas três últimas décadas, em que diversas significações e sentidos lutam por se fazer presentes, por impor uma única verdade, universalizar-se e controlar a multidão de discursos, monologizar e finalizar o diálogo.

O convite é para que se compreendam as considerações sobre a leitura como matéria-prima social disponível, a partir da qual surgem novas significações e vozes sociais.

\section{1 A unidade e o uniformizante}

Um dos significados, com grande influência em variadas esferas sociais, designa a leitura como ato invariável e único, com efeitos homogêneos sobre os sujeitos. A partir de um quadro epistemológico de tradição etnocêntrica, universalizante e uniformizante, a Leitura ${ }^{6}$, assim compreendida, assumirá nuances que privilegiam a unidade e apagam a diversidade.

Essa significação opera com conceitos, convenções e práticas que privilegiam uma determinada formação social, como se essa fosse natural ou universal ou o ponto de chegada de um curso normal de progresso e desenvolvimento. Define-se pela maior ou menor proximidade àquilo que se constituiu como legítimo e por sua relação com a Cultura que se quer dominante (GALVÃO; BATISTA, 1999). O ato de ler, além de altamente desejável a todos, "pode ser posto a serviço de todas as causas de sociedades alfabetizadas" (HÉBRARD, 1996, p. 35), com poderes para transformar mentalidades, valores, consciências e hábitos e "capaz

indicador mais sensível de todas as transformações sociais". (BAKHTIN [VOLOCHÍNOV], 1981, p. 41). Essa dimensão saturada e multissêmica das palavras, que não se esgotam em significados estáticos e dicionarizados, decorre do conceito de dialogismo.

6 Neste texto, o termo Leitura com inicial maiúscula indica sua filiação a uma perspectiva etnocêntrica e universalizante, outorgando ao ato de ler o mesmo estatuto dos substantivos próprios, de caráter unitário.

VÓVIO - Construções identitárias... 
de eliminar barreiras sociais, culturais e econômicas" (ABREU, 2001, p. 141).

Essa abordagem pode ser identificada em estudos sobre a leitura que oferecem as bases para o desenvolvimento de políticas culturais e educacionais e em estudos sobre a história do livro que buscam identificar a difusão do hábito da leitura na população, as escolhas dos leitores em matéria de títulos e gêneros que compõem bibliotecas e os objetos da produção cultural numa dada época e para determinados grupos. A ênfase desses estudos recai nos sujeitos (quem), nos objetos (o quê), no onde e no quando da leitura, sendo a posse do material impresso determinante dos leitores e das leituras.

Consoante a esse enfoque, também se encontram pesquisas desenvolvidas nas décadas de 1960 e 1970 voltadas a demonstrar que a escolarização, a aquisição da linguagem escrita e o acesso à leitura seriam sinônimos de progresso social e responsáveis pelo desenvolvimento cognitivo e pela aquisição de conhecimentos necessários para adequar-se a sociedades modernas ${ }^{7}$. Os expoentes desse modelo de interpretação trataram o domínio da linguagem escrita como independente do contexto social, como variável autônoma com conseqüências intrínsecas para a sociedade e para a cognição. Sujeitos, grupos e sociedades são tomados como receptores passivos, sobre os quais os efeitos seriam homogêneos. Seus pressupostos orientaram pesquisas e influenciaram legislações, políticas públicas, programas e ações na esfera estatal (KLEIMAN, 2001b).

Os discursos do déficit e da precariedade advindos desse enfoque são a outra face da mesma moeda: de uma Leitura mitificada e redentora, atravessando a história da leitura no Brasil em diversos períodos. Segundo Abreu (2001), esses discursos são "decorrentes da delimitação implícita de um certo conjunto de textos e de determinados modos de ler como válidos e o desprezo aos demais" (p. 154). Partem de uma premissa comparativa entre sociedades constituídas a partir de contextos sociais, políticos, econômicos e culturais extremamente distintos, demarcando as distâncias que separam as práticas letradas hegemônicas das de segunda categoria, ou "bastardas".

\footnotetext{
7 Nessa vertente, ver as produções de Goody (1987), Ong (apud RIBEIRO, 1999b), e Olson e Torrance (1995).
} 
Nessa perspectiva, o livro e alguns gêneros literários e de divulgação científica são os maiores representantes da Cultura a que todos deveriam ter acesso, seguidos dos jornais e revistas, depreendendo-se daí os critérios que definem os bons e os maus usos da leitura. Ao estabelecer uma hierarquia de objetos, de gêneros e de suportes, aqueles que se filiam a esse enfoque não só definem o que é ler mas também escalonam os leitores segundo os objetos que consomem, as oportunidades de acesso e a freqüência com que lêem, excluindo os não-leitores (ABREU, 2001; TARDELLI, 2003).

Um enfoque sobre a leitura calcado numa visão elitista de cultura torna invisíveis as práticas comuns de leitura. Ao enfatizar determinada leitura como única e legítima, mantém nossa atenção num conjunto restrito de possibilidades de praticar a leitura. Muitos pesquisadores, como Street (1984) e Kleiman (1995), defendem a necessidade de mudança das lentes com as quais se observa o mundo social e as práticas humanas, a partir de uma percepção fundada nas idéias de multiplicidade, heterogeneidade e variação nos modos de praticar a leitura, nos objetos dados a ler e nas formas de apropriação do texto pelos sujeitos.

\subsection{A diversidade sob dois estatutos}

Outro enfoque sobre a leitura é aquele fortemente influenciado por uma matriz culturalista e da diversidade. Uma de suas características principais é desnaturalizar práticas humanas e dissolver qualquer movimento em torno de uma unidade cultural ou de um pretenso destino evolutivo para o qual todas as sociedades rumariam. As práticas culturais são tomadas como criações humanas variáveis e, como conseqüência, tem-se a distensão do campo das práticas de leitura.

Essa abordagem amplia o horizonte dos objetos da leitura, dos modos, comportamentos e preferências frente ao ato de ler, quebrando dicotomias entre objetos melhores e piores, leitores e não leitores, e, sobretudo, eliminando a aura de inacessibilidade a certos materiais e gêneros de leitura. Tem o potencial de fazer emergir uma variedade de práticas e de vozes e discursos apagados ou não reconhecidos por um

VÓVIO - Construções identitárias... 
enfoque etnocêntrico, permitindo a manifestação de pluralidade no interior de sociedades e grupos humanos. ${ }^{8}$

\subsubsection{A diversidade sob a perspectiva da neutralidade}

Uma de suas variantes opera sob o estatuto da neutralidade e da equivalência entre as diferenças, por um lado, e da defesa de certas práticas, objetos e leitores pertencentes a grupos minoritários ou ameaçados por processos de não reconhecimento ou de estigmatização, por outro. Ocupa-se do reconhecimento de igual dignidade de universos simbólicos, da tolerância e respeito em relação a práticas culturais diversas.

É o estatuto da neutralidade o aspecto mais criticado nessa vertente, que dá suporte a pesquisas que focalizam a mera descrição de práticas, objetos e leitores, reduzidos a traços colecionados e descritos em si mesmos, sem que se compreendam seus lugares sociais e sem relacioná-los à ordem simbólica e aos sistemas em que são produzidos. Chartier (2003, p. 153) lembra que "as práticas culturais são sempre o objeto de lutas sociais que têm por risco sua classificação, sua hierarquização, sua consagração (ou, ao contrário, sua desqualificação)", não podendo, portanto, ser tomadas como um mundo à parte, com um valor determinado pela distância que se encontra da legitimidade cultural da qual é privada.

Nesse enfoque, corre-se o risco de substituir um padrão por outro. Em vez da Leitura, do legítimo e digno, do hábito e da freqüência com que leitores (idealizados) acessariam certos gêneros, a ampliação de universos culturais levaria à valoração por si de produções locais, de leitores singulares, de leituras e objetos multivariados.

O estatuto da neutralidade pode corresponder à atitude ética de defensores das culturas minoritárias e dos grupos em situação de maior vulnerabilidade no campo social, exigindo condição de igual valor das produções culturais, tanto desses grupos como dos grupos dominantes. Mas, também, pode corresponder a uma atitude complacente do forte

\footnotetext{
${ }^{8}$ Ver as proposições, no campo da História da Leitura, de Chartier (2003), dos estudos sociológicos, de Lahire (2006) e, da Lingüística Aplicada, de Kleiman (1995, 2002a).
} 
em relação ao fraco, daquele que, assegurado da legitimidade cultural, pode tolerar e admitir o(s) outro(s) (CUCHE, 2002).

A neutralização das contradições econômicas e sociais no interior de sociedades altamente hierarquizadas não é prática neutra. As culturas originam-se nas e a partir de relações sociais, marcadas pela desigualdade, por assimetrias entre culturas e que resultam da própria hierarquia social. O processo de neutralização da ordem simbólica reveste-se de uma intenção democrática que tem como conseqüência a imobilidade.

O reconhecimento da diversidade sob esse estatuto pode resultar numa ação compensatória. Pode, por consagrar a diversidade, propor uma ação de substituição de um padrão por outro, um novo padrão cujo valor simbólico não é equivalente no jogo social. E pode, ainda, propor uma ação ética da tolerância e do respeito, sem que as diferenças sejam discutidas em sua origem e resultados sociais.

Reconhecer que as práticas culturais relativas à leitura encontramse em maior ou menor grau atravessadas por conflitos e lutas sociais não deve reduzir seu estudo somente às lutas sociais. Este tipo de análise também leva ao imobilismo, em especial quando suas interpretações são redutoras ou deterministas, supondo "que o mais forte está sempre em condições de impor pura e simplesmente sua ordem (cultural) ao mais fraco" (CUCHE, 2002, p. 145).

\subsubsection{A diversidade sob a perspectiva sócio-histórica e ideológica}

Esta vertente estabelece uma relação de interdependência entre três pressupostos: as diferentes práticas de leitura, a multiplicidade de maneiras de ler e de objetos da leitura e a variação gerada pelas condições sócio-históricas e culturais As práticas de leitura não se encontram inextricavelmente relacionadas a um único objeto (o livro), não se definem por uma forma particular de ler (silenciosa e solitária). Não se localizam exclusivamente na mente das pessoas, como um conjunto de habilidades a serem aprendidas, e também não residem nos textos. Não podem ser alcançadas meramente pela determinação de sua freqüência e hábito, pela posse de objetos de leitura ou pelo pertencimento estrito a classes ou grupos. Como toda atividade humana, a leitura é essencialmente social e pode ser localizada na interação entre as pessoas (KLEIMAN, 1995, 2001a).

VÓVIO - Construções identitárias... 
Essa abordagem é assumida pelos Estudos do Letramento, que concebem as práticas de uso da escrita como algo necessariamente plural: sociedades diferentes e grupos sociais que as compõem têm variadas formas de letramento, tendo a escrita variados efeitos sociais e mentais em contextos sociais e culturais específicos. O reconhecimento, por Street (2004), dos problemas de uma abordagem etnocêntrica das práticas de uso da escrita em diferentes sociedades e grupos humanos permitiu uma compreensão etnográfica e teoricamente mais adequada dos significados das práticas letradas na vida das pessoas. No Brasil, Kleiman (KLEIMAN, 1995, 2002b, 2005) tem sido um dos expoentes dessa abordagem em pesquisas e no debate no campo do ensino da língua materna. Para ambos os autores, é preciso debruçar-se sobre os fatores sociais, considerando as diversas esferas da atividade humana, determinadas por sua inserção cultural. As práticas letradas, a leitura, a escrita e a oralidade são tomadas como fundamentalmente ligadas às estruturas sociais, interpenetradas em complexos sistemas culturais e dentro de estruturas de poder.

Nessa perspectiva, é preciso olhar para as elaborações, procedimentos e demandas a que os sujeitos devem responder em diferentes situações de seu cotidiano e para as posições em que se encontram (tanto nos eventos como no campo social mais amplo), já que nas ações humanas entram em jogo as relações de poder, as tensões, as desigualdades que caracterizam a vida social, política e econômica (ZAVALA; NIÑO-MURCIA; AMES, 2004). As práticas de letramento adquirem significado e concretude em contextos sociais relacionados às atividades $e$ às interações que ocorrem no interior das culturas, especificamente nos eventos mediados e organizados pela escrita. Leitores interagem em distintos mundos letrados, instanciados pelos instrumentos culturais de que dispõem e de que podem lançar mão (nesse caso, gêneros da escrita) e mediados por relações interpessoais.

Embora não seja um enfoque dominante no campo da leitura, a abordagem sócio-histórica e cultural propiciou a revisão da postulação dos efeitos homogêneos da aprendizagem da escrita sobre os sujeitos (cf. VÓVIO, 1999; OLIVEIRA; VÓVIO, 2003), a formulação de novas orientações para o desenvolvimento de abordagens de aprendizagem da linguagem escrita, a constatação de que as pessoas, ao compartilharem práticas de uso da escrita, constroem conhecimentos, antes mesmo de 


\section{8}

ocuparem os bancos escolares. Tem ainda amplificado a atribuição educativa e complexificado a formação de leitores, pois o que se espera dos atores sociais está relacionado simultaneamente às demandas culturais mais amplas e àquelas preconizadas por instituições ou domínios sociais onde as práticas de leitura se materializam.

\section{CONSTRUÇÃO DE IDENTIDADES}

Neste artigo, a análise da construção identitária dos participantes contemplou a reação-resposta à pergunta colocada numa das rodas de conversa na geração de dados - Que leitor ou leitora sou eu? Nesse processo adotou-se uma perspectiva lingǘstico-enunciativo-discursiva a fim de identificar as vozes sociais que constituem seus enunciados e o modo como entram na composição de seus discursos (que efeitos de sentido produzem), o que os coloca em relação, mas não de modo definitivo, aos enfoques correntes (a outras vozes sociais) sobre a leitura e sobre os objetos que se prestam ao ler. Também interessava verificar movimentos de mudança e de transformação, porque, ao se apropriarem de significados estáveis e colocá-los a favor da interação em que estão envolvidos, os participantes atualizam, refutam ou reacentuam-nos em seus enunciados, em função da identidade dos interlocutores, da finalidade da enunciação, do momento histórico e da ideologia (BAKHTIN, 1993). Esse processo de individualização do discurso, de atualizar e de torná-lo em próprio é decorrente de uma complexa rede de significação, e surge do diálogo social, como prolongamento, como réplica.

Três estilos emergiram nas respostas. Esses estilos não resultaram de escolhas casuais dos sujeitos; e os enunciados não diziam respeito a produções independentes, sem ligação com a cadeia de comunicação verbal estabelecida localmente, no contexto, e globalmente, a partir do horizonte sócio-histórico em que estão inseridos. Essas produções conectavam-se com as intenções, posicionamentos e relações sociais próprias da situação discursiva.

A leitura tem o estatuto e o poder de colocar os sujeitos em outro lugar na escala cultural e de transformar suas vidas, pelo menos no que 
diz respeito ao acesso à cultura escrita, da qual o livro é tido como principal representante. Perpassam seus enunciados vozes consoantes a um enfoque legitimador da Leitura, mas os alfabetizadores-participantes as acionam por meio de táticas voltadas à autolegitimação (como em DE CERTEAU, 1994), produzindo efeitos que, num mundo cultural altamente hierarquizado, preconceituoso e diferenciador, rompem com uma ordem que se impõe a grupos em relação assimétrica na hierarquia societária, e quebram certas expectativas sociais.

A seguir, são apresentados cada um desses estilos, com suas principais características, situados a partir de exemplares de enunciados das participantes.

\subsection{A essencialidade na produção de identidades}

Em quatro casos (MA, AP, FB e $\mathrm{DN}$, esta última de modo ligeiramente contrastante) observou-se um movimento de aproximação e adesão à proposta da pesquisadora. Essas alfabetizadoras-participantes estruturaram suas respostas a partir da operação de qualificação de si, realizada por meio do verbo ser: eu sou uma leitora $+\underline{\text { atributo. }}$. Alinharam-se à interpelação da pesquisadora, retomando em seus dizeres partes da pergunta posta na roda, aceitando o pressuposto (ser leitora). Ao se autoqualificarem, expressam apreciações de caráter positivo sobre si mesmas por meio de adjetivos avaliativos (crítica, investigativa, curiosa), operando estratégias no sentido de estabelecer o que são e, no mesmo movimento, o que não são.

A identidade em seus enunciados se configura como uma questão de ser, de essência. Seus dizeres sobre si e o modo como o dizem são atravessados pela tensão de serem reconhecidas na representação que produzem de si mesmas: se é preciso afirmar-se como leitoras, é porque há possibilidade de existirem outros que não são leitores e, ainda, pessoas que não as reconheçam como tais. Esta tensão, própria do estilo com que constroem suas respostas, parece indissociável da assertividade com que enunciam e da positividade com que se representam como leitoras. Um exemplar típico desta ocorrência é MA, quem primeiro enuncia sua identidade leitora, apoiada por suas colegas.

Todo mundo olha pra mim ((risos)) Eu sou uma leitora muito crítica, entendeu? ... Porque quando eu leio alguma coisa assim... 
Eu gosto de ler muito ficção, romance, poesia... Quando eu tô lendo algum livro que eu vejo que não tem conteúdo, não tem nada a ver, o contexto não bate com o que eu quero, que eu espero que seja o livro, eu automaticamente, eu deixo o livro de lado... Eu não leio mais... Tenho mania de ler o começo do livro, o meio do livro e o final do livro, aí eu sei se o livro é bom... Porque quando eu vou escrever às vezes a minha escrita das minhas poesias, das coisas que eu faço, é muito do momento e do que eu leio também... Então, eu gosto de ler muito jornal, críticas de jornais, muita política, muito esporte... Então, eu sou mais uma leitora crítica assim... Policio muito o que eu leio /.../

A partir dessa auto-atribuição, que a caracteriza como crítica, e pelo intensificador muito, MA aponta aquilo que lhe confere uma identidade leitora. Seu enunciado dirige-se para instituí-la como leitora capaz de emitir opiniões sobre o que lê, de criticar e de julgar um gênero, livro ou texto. Ela compartilha o sentido do que seja uma leitora muito crítica, configurando-a a partir da capacidade de julgar e avaliar esteticamente objetos de leitura, de atos de ler circunstanciados, de modos de ler, de condições para ler integralmente ou não um livro, da freqüência e da seleção de objetos (além dos livros, os jornais também são mencionados), de gêneros e temas de seu interesse. $\mathrm{O}$ uso reiterado do pronome pessoal de primeira pessoa nas construções predicativas com ser, ou com verbos de atitude e de volição conjugados no presente do indicativo de temporalidade ilimitada, que enuncia verdades absolutas ("eu sou uma leitora, eu gosto, eu quero, eu vou, eu deixo, policio"), confere valor de verdade, de responsabilidade, de assertividade e de agência: são esses os elementos que a instituem como sujeito capaz de intervir no mundo social.

MA dispõe ainda uma combinação de propriedades capazes de dar suporte à sua apreciação. Esse modo de configurar-se como leitora influiu diretamente nos processos identitários em curso de todos os participantes: os atributos usados por ela foram retomados nas réplicas de outros alfabetizadores-participantes ${ }^{9}$ tanto para identificar-se como para se diferenciar e introduzir outros.

\footnotetext{
9 A "réplica" está aqui sendo entendida de acordo com o sentido que Bakhtin (1981) lhe atribui.
}

VÓVIO - Construções identitárias... 
Essa alfabetizadora configura-se como sujeito capaz de realizar as ações, de avaliar o que merece ser lido integralmente, de selecionar e de policiar suas leituras. Para tanto, lança mão de símbolos da tradição cultural da leitura e da chancela escolar: objetos e gêneros (livros, jornais, ficção, romance, poesia, críticas de jornal) disposição ("eu gosto muito..."), correlação entre leitura e escrita ("Porque quando eu vou escrever às vezes a minha escrita das minhas poesias, das coisas que eu faço, é muito do momento e do que eu leio também...”). Ela apresenta-se também como leitora que sabe percorrer uma obra e mapear campos de interesse de acordo com as finalidades que estabelece ("Quando eu tô lendo algum livro que eu vejo que não tem conteúdo, não tem nada a ver, o contexto não bate com o que eu quero, que eu espero que seja o livro, eu automaticamente, eu deixo o livro de lado..."). Seus dizeres mostraram-se entretecidos por vozes sociais que atribuem aos leitores a capacidade de apreciar e julgar obras e de consumir certos bens culturais, os livros (KLEIMAN, 2001b). Porém, no mesmo movimento, MA não se coloca como subordinada às convenções e aos símbolos da tradição, estabelecendo ruptura com a representação da Leitura.

Assim como MA, as outras alfabetizadoras também identificam propriedades pessoais, que dizem respeito às suas leituras preferenciais, às competências adquiridas, aos modos como lêem, aos seus sentimentos, às suas disposições, ao hábito e à freqüência com que praticam a leitura. Suas escolhas viabilizam seus projetos de dizer por meio de propriedades que povoam o discurso hegemônico sobre a Leitura e as autolegitimam frente aos padrões sociais. Vozes sociais da educação escolar foram indiciadas em seus discursos, nos modos e convenções sobre o ato de ler, nos materiais que identificam e na disputa em torno da leitura extensiva ou intensiva. Outras vozes sociais indiciadas dizem respeito à leitura por prazer, por gosto, alimentada pela curiosidade versus aquela cuja finalidade é sua aplicação concreta e imediata, pragmática.

Todos esses elementos são dispostos nos enunciados das quatro participantes como atributos que lhes são próprios e não apropriados. Não recorrem às experiências passadas para dizerem de si como leitoras; não mencionam pessoas, processos ou âmbitos sociais que exerceram influência em sua formação. São propriedades que não estão à mercê de alterações em razão de circunstâncias excepcionais que possam acometê- 
las; são tratadas como constitutivas de sua identidade. Ser leitora, em seus discursos, é um traço identitário essencial.

\subsection{A apreciação na produção de identidades}

Nesse grupo estão incluídos os enunciados de MI, CD e DG, que reagiram numa outra orientação argumentativa que não a instada diretamente pela pergunta. Eles não se designaram como leitores e não se autoqualificaram diretamente, mas construíram seu auto-retrato como leitores indicando um estado emocional genérico frente ao ato de ler (eu adoro, eu gosto, eu não gosto) e não um conjunto de atributos e propriedades pessoais. A construção identitária nesses casos supõe uma capacidade cognitiva, associa-se à possibilidade de apreciar o próprio ato e apreciar esteticamente obras. Um exemplar deste agrupamento é MI, sexta educadora a entrar na roda.

Eu adoro ler... A::h... meu nome é MI... Eu adoro ler... Mas ao contrário da $\mathrm{MA}$ e da DN... eu quando eu não... Assim que eu começo ler o livro que eu vejo que eu não tô gostando eu jogo pra lá... Não quero mais... Eu vou procurar outros... que têm que começar BOM... Eu sempre deixo assim... É adoro ficção também/

$\mathrm{Na}$ sua reação-resposta, ela não responde diretamente à pergunta, não atribui a si mesma uma qualificação, mas declara um julgamento que diz respeito genericamente ao ato de ler. Ela esquiva-se de uma autoqualificação explícita, mas, implicitamente, declara ser uma leitora apaixonada: "eu adoro ler", com o sentido estativo (ter o hábito, ter a inclinação). $\mathrm{Na}$ seqüência, introduz o conector argumentativo mas, que orienta para um acréscimo em sua caracterização, um modo de ler, colocando-a em relação à disputa de modos de ler estabelecida anteriormente por outros participantes (abandonar a leitura ou ler um livro até o fim). A conclusão contrária cria uma nova identificação para si e, ao mesmo tempo, uma diferenciação de sua condição frente aos seus interlocutores. Ela não é uma leitora que segue a norma de ler até o final, ação que atribui a MA e DN.

VÓVIO - Construções identitárias... 
Esse traço identitário, de não seguir a norma da leitura integral, dogma que figura na representação da Leitura, também se expressa nas ações realizadas quando suas expectativas de fruição (estar gostando de) não são atendidas: "Assim que eu começo ler o livro que eu vejo que eu não tô gostando eu jogo pra lá... Não quero mais... Eu vou procurar outros”. Ela é quem decide o que merece ser lido ou não. A leitura integral de um livro é dirigida por sua avaliação: "que têm que começar BOM".

MI projeta também, como outros o fizeram antes dela, a imagem de um sujeito ativo e que exerce controle sobre suas escolhas e ações. No seu caso, essa capacidade é expressa de modo genérico, o que a coloca próxima ao hábito e, portanto, da predicação existencial: a afirmação "eu adoro ler" implica "eu leio", o que, por sua vez, implica assumir-se como leitor. Quanto a CD, apesar de, no seu enunciado, ter expressado sua apreciação positiva do ato de ler, o modo como o associa a objetos caracterizados de modo pejorativo, assim como a hesitação com que a pronuncia, perturbam a construção da imagem de leitor em curso. Procura reparar esses traços negativos à medida que contrasta a prática de leitura inicialmente declarada com a de outros membros do grupo, que se dedicam à leitura intensiva do livro e que gostam de ler. Já DG não concorda com o pressuposto da pergunta posta e caracteriza-se pela negação (“eu não gosto de ler"), projetando na roda uma imagem de si conflitiva, hesitante e negativa, a partir do modo como se configura como leitor. A idealização de leitor e de certas práticas leva-o a uma autodepreciação, mas também está explícito na sua fala o desejo de mudança ("então eu queria poder ler mais") e de ampliar o acesso a práticas de leitura, expectativa que declarou na primeira roda de conversa.

Os retratos de leitor e os modelos de leitura produzidos pelos três alfabetizadores-participantes desse grupo partem de estados subjetivos, particulares, que seguem critérios que não são convencionais, mas guiados por interesses individuais. Para aqueles que dizem gostar de ler (MI e CD), essa condição admite um relaxamento em relação à imagem de leitores idealizados e às leituras legitimadas; abre um campo de possibilidades mais distenso, no qual pode haver uma prática associada ao prazer. DG, no entanto, dá a conhecer uma condição negativa, mas, 
alternativamente, revelando a falta, talvez apresente o desejo de alçar-se a outra posição frente à leitura e sua identidade leitora.

\subsection{A narração na produção de identidades}

Desse grupo fazem parte três alfabetizadoras (AL, RZ e MD), que também reagiram numa orientação que não a instada pela pergunta, e produziram pequenas narrativas e relatos, contando suas histórias de formação como leitoras. Lançar mão da narrativa de experiência pessoal para produzir suas respostas coloca-se a favor da explicitação tanto do caráter dessa representação, a de um processo vivido, como de posicionamentos que significam esse processo — passar de uma posição particular na escala social e cultural a outra. Também permite explicitar o modo como produzem táticas para driblar as condições desfavoráveis a que estavam submetidas. Como aponta Bakhtin (2003), na narração sobre a própria vida, que pode assumir um caráter prático e objetivo, o $e u$ que conta a vida é também o outro no discurso, "é o outro possível, que se infiltrou na nossa consciência e freqüentemente dirige os nossos atos, apreciações e visão de nós mesmos ao lado do nosso eu-para-si; é o outro na consciência" (p. 140).

Como uma narração e auto-reflexão, esses discursos estão fortemente marcados pela menção de estados e condições subjetivas, da descrição de ambientes e condições de vida, de experiências pessoais passadas ou recentes, de opiniões e pontos de vista sobre si mesmo, sobre os outros e sobre os acontecimentos e vivências. Relacionam-se, portanto, à capacidade de autoconsciência, que emerge à medida que os sujeitos interpretam, valoram e distinguem os acontecimentos que compõem sua história com a leitura, muitas vezes pontuadas por intercalações que suspendem a narrativa e dão espaço a seqüências avaliativas e explicativas.

Um exemplar desse estilo é o de RZ:

É... Eu não tinha hábito de ler... Passei a ter depois que fui pra faculdade né? Um pouco pela necessidade, que eu faço literatura... Então, eu acho que tem que ler bastante... Tive vários conhecimentos de livros e passei a gostar e se eu pego um, não importa o tamanho, eu leio até o fim... Embora o tempo é

VÓVIO - Construções identitárias... 
corrido, a gente às vezes precisa ler na condução, mas eu vou até o fim... Gosto assim de ser curiosa... O que acontece? O que o autor quis dizer né? Eu gosto de ler até o fim... O pouco que eu leio, eu leio até o fim/

As enunciações anteriores colocaram em jogo valores e posicionamentos sobre a leitura, livros e leitores, assim como alguns conteúdos temáticos que serão retomados por RZ e também por AL e MD. No entanto, a produção discursiva das três estabelece uma relação de anterioridade e posterioridade entre os fatos narrados em relação ao momento da enunciação. Elas determinam um ponto inicial: um estado de ausência ou de negação no enunciado indiciado pelo advérbio (não) predicado de ações passadas, sinalizado pelo pretérito imperfeito (tinha e gostava) que diz da condição que se modificara. Em RZ, há um antes semo hábito, sem praticar a leitura.

RZ dá a conhecer uma nova situação a partir de um ponto de viragem que inaugura o processo em curso, por meio do uso de verbos incoativos, com perífrases que expressam aspecto inceptivo, de início do evento (passei a ter) e pelos marcadores temporais (depois e então). Esses marcos variam em cada caso, mas são todos resultantes de um forte investimento pessoal, como a menção da entrada no ensino superior em RZ.

A seguir, conta do ingresso no mundo da leitura; não da leitura de qualquer objeto, mas do livro, objeto que complementa o ato de ler, do qual se obtém conhecimentos e que pode promover a formação do leitor: "tive vários conhecimentos de livros [...]". Nota-se em todos os casos o uso reiterado do pronome pessoal de primeira pessoa e dos verbos que expressam apreciações subjetivas e indicam processos e ações desencadeados por elas.

RZ volta-se para a narrativa de seu processo, estabelecendo uma relação causal originada no acesso: adquirir o hábito e tomar gosto relacionam-se ao fato de ter adquirido "conhecimentos de livros" no seu curso. Tanto o hábito como o gosto ligam-se a um modo de ler — ler até o fim - com um tipo de disposição do leitor, a curiosidade. Todas as propriedades mencionadas nos enunciados que a antecederam, e que carregam a autenticação de um padrão escolar, são ícones desse modelo 
e compõem o ideário de um enfoque sobre a leitura fortemente disseminado, tanto na educação escolar (campo em que transita como estudante e profissional), como no cotidiano (por meio de campanhas educativas, imagens e mensagens veiculadas pela mídia).

A pressão exercida pelo auditório - pelas vozes desse discurso polifônico - para criar certos efeitos de sentido parece levar as educadoras a relatarem o processo de forma linear e progressiva e a reiterar a disposição adquirida, a positividade com que enfrentaram obstáculos e os resultados obtidos. Desse modo, omitem-se contradições, problemas, desvios e ambigüidades e se apontam causas. Seus percursos não são os esperados, dada a situação de vulnerabilidade social. São relatos de sujeitos representados como ativos, que mudam suas condições sociais de origem e que fazem escolhas dentro das fronteiras de uma certa legitimidade que conhecem.

RZ termina seu relato com os resultados e com o balanço positivo sobre a mudança operada: é uma leitora que adquiriu o hábito de ler livros, de lê-los até o fim. A mesma operação é observada nos relatos de AL e MD. Nesse momento, os verbos passam a ser conjugados no presente do indicativo, dando a dimensão de um ponto de chegada. Contam de seu estado atual: são leitoras. MD tem o hábito, lê porque exigem, mas escolhe os livros; AL tomou gosto pela leitura, ampliou o conjunto de objetos lidos (os jornais, as revistas, objetos valorados positivamente na sociedade), sabe interpretar poesias. São a leitura e o fato de ser leitor o ponto de chegada de progresso e desenvolvimento pessoal, nos três casos.

Os enunciados deixam entrever a consciência da diferença, da distância da Leitura em que se encontrariam - aquela veiculada pelo discurso dominante que impõe padrões, objetos e modos de ler - pelo fato de pertencerem a grupos sociais empobrecidos. Apesar dos obstáculos e das dificuldades financeiras enfrentadas em suas vidas, isto é, de um estado inicial desfavorável, tornaram-se leitoras. Esses aspectos encontram-se implícitos nos discursos, mas podem ser acessados pelo exame de suas condições de vida e do horizonte social em que se encontram. Para as três, nesse contexto, vencer, quebrar barreiras impostas pela ordem social é importante.

VÓVIO - Construções identitárias... 


\section{AUTOLEGITIMAÇÃO E MOVIMENTAÇÃO CULTURAL}

Ser leitor com determinadas propriedades, adquirir o hábito e as competências; identificar comportamentos favoráveis e apreço pela leitura; e ser ativo e poder ler de variados modos, isso se atualiza nas significações que atravessam os discursos desses alfabetizadores. São construções identitárias que creditam à leitura e aos leitores lugares sociais diferenciados, que tomam o ato de ler como condição para a incursão em novas práticas e novas identidades, como que promovendo deslocamentos em maior ou menor grau frente aos grupos de origem. $\mathrm{O}$ livro é apresentado como elemento que afiança as identidades que produzem e como elemento importante neste ponto de viragem em sua trajetória cultural. Subjaz em seus enunciados a crença no poder transformador de uma prática cultural, a Leitura, e no poder do livro.

A busca da autolegitimação por meio da leitura, da apropriação de objetos culturais e da produção de uma imagem de leitor competente, ou a necessidade de tornar-se leitor, só existe em sociedades, grupos ou comunidades que crêem na sua importância, na superioridade de práticas consagradas e distintivas e nos bens relacionados ao universo da cultura escrita. No Brasil, onde uma elite letrada tem usado a educação escolar e a cultura escrita como instrumentos para exercer o poder e manter hierarquias sociais, negando ou dificultando àqueles em situação de maior vulnerabilidade social seu acesso e apropriação, o percurso formativo dos alfabetizadores-participantes pode ser considerado surpreendente ou, até mesmo, improvável (KLEIMAN, 2001a; VÓVIO; SOUZA, 2005).

Essa crença e o peso social a ela atribuído pelos alfabetizadoresparticipantes concorreram para a representação de suas pessoas. $\mathrm{Na}$ análise da construção identitária em curso pôde-se observar os recursos que cada educador-participante reuniu, tanto para construir a si mesmo em relação ao(s) outro(s), como para construir seu auto-retrato de leitor. A operação de construção de imagens de si, como assevera Amossy (2005), se dá, de modo deliberado ou não, nas trocas que se efetuam na comunicação, nas quais cada um projeta imagens valorizantes de si e adequadas ao contexto em construção. 
É a maneira de dizer o que permite a produção de imagens de si; é sob a ótica dessas imagens projetadas (previamente, antes mesmo do dito, e na situação) que os interlocutores estabelecem inter-relações (MAINGUENEAU, 2005). Essas imagens de si conferiram aos enunciadores, e aos seus interlocutores, status e lugares que se colocaram a favor da outorga de legitimidade ao seu discurso, e, portanto à sua identidade como leitores. Também afiançaram seus dizeres frente aos outros, tendo como um de seus efeitos a criação de uma comunidade, a partir da adesão a determinadas posições e pontos de vista sobre leitores e práticas de leitura.

Os efeitos cumulativos das formas lingüístico-enunciativas utilizadas para construírem sua identidade leitora resultaram em um conjunto de traços marcantes, que diferem de outras pesquisas nas quais se investiga a auto-imagem de professores ou educadores. Exemplo disso é a pesquisa desenvolvida por Rosa (2003), com professores do ensino fundamental da rede municipal do Recife:

No grupo estudado predominaram formas negativas nas descrições de si-mesmas como leitoras. A leitura foi percebida como uma prática compulsória e sem maior significação. Elas se distanciavam de seu modelo ideal, expressando um sentimento de inadequação. (p. 137).

Naquele estudo, as professoras lançam mão de propriedades que as desqualificam como leitoras. Apresentam-se como falhas, vazias, inexperientes, infantis, com problemas para ler, entender e escrever. Em seus relatos autobiográficos prevalecem dois movimentos: o da autodepreciação e o da expressão do desejo de mudança. Orientam-nas nessa construção identitária os discursos da crise da leitura e do enfoque hegemônico da Leitura. Observam-se a partir da figura idealizada de leitor (um impossível), que lê somente objetos dignos, e, assim, desconsideram suas experiências, práticas e contextos nos quais lêem e escrevem e ensinam a ler. Os jogos de classificação sociais que perpassam a construção de imagens de si certamente dizem mais sobre as categorias de percepção desses sujeitos do que suas práticas efetivas (LAHIRE, 2006).

Kleiman (2001b, 2006) tem discutido os efeitos do processo intenso de desvalorização profissional dos alfabetizadores e professores 
de língua materna e da forma como esses profissionais têm sido colocados constantemente em xeque pela mídia, por gestores de políticas públicas e por pesquisadores, em relação aos seus saberes e às competências para ensinar a ler e a escrever. Segundo a autora, esse processo de estigmatização e produção de estereótipos calcados em preconceitos e em mitos sobre a escrita e seus efeitos homogêneos sobre os sujeitos influi no modo como se percebem e se constroem identitariamente como profissionais da educação. Em artigo recente (KLEIMAN, 2006), ela contrasta representações e posicionamentos de professores e educadores populares, concluindo que, nos discursos produzidos por professoras, elas recorriam a formas negativas verbais e a expressões impessoais, genéricas, aspectos que contribuem para a constituição de sujeitos impotentes diante das "ações sobre as quais elas não têm poder para modificar" (p. 3).

$\mathrm{Na}$ investigação em pauta, um traço marcante nos enunciados dos alfabetizadores-participantes e observado em todos os casos é o uso intensivo e reiterado do pronome pessoal de primeira pessoa eu (também me e mim). Essa característica coloca-se a favor da representação de papéis assumidos por eles, posicionando-os como sujeitos na produção de seus discursos e como protagonistas de sua história. Sete alfabetizadores-participantes usaram pronomes pessoais de primeira pessoa (eu, me, para mim) na posição de sujeitos que realizam ações mentais (eu leio, en sei, para mim criticar, en policio, para me informar, en vou escrever, eu vejo [no sentido de julgar]); que agem no mundo (eu leio, eu pego, eu vou atrás, eu largo, eu continuo); que acionam e desenvolvem processos (comecei a me interessar, eu comecei a ler, passei a gostar); que sentem (eu gosto, eu adoro); que atribuem qualidades positivas (enunciados com o verbo ser e expressões predicativas que as qualificam de modo positivo, como: eu sou uma leitora muito crítica, investigativa; en sou curiosa). Todos eles se apresentaram a partir de um $e \boldsymbol{u}$ agente, capaz de transformar situações, de perceber-se, e que tem consciência de si mesmo e dos processos que desenvolve (mesmo no caso de DG, o uso do pronome pessoal aparece como sujeito em negações, capaz de abonar a avaliação que faz de si e as declarações sobre como se percebe diante do ato de ler).

O comportamento assertivo é outro traço da imagem que projetam nas rodas, exceção feita a DG. Constroem imagens de si afirmando características e competências que autenticam a condição de 
leitoras, colocam-se como capazes de ajudar outras pessoas, de dar ensinamentos e aconselhar, de fazer escolhas, enfim, apresentam-se como pessoas que reúnem um conjunto de comportamentos que julgam também apreciados positivamente por seus interlocutores e, especialmente, pela pesquisadora. Foram raros os enunciados em que aparecem afirmações ou negações atenuadas ou nos quais mostram incerteza, dúvida, hesitação ou não responsabilidade frente ao que dizem sobre si mesmas.

A positividade é realçada em seus discursos a partir do modo como descrevem a superação de obstáculos e desafios, no modo como narram suas histórias, nos adjetivos que utilizam para se autoqualificarem, no modo como se percebem e descrevem seu comportamento. Mostram-se ativas e sujeitos das ações que realizam para alterar uma situação difícil ou para modificar suas condições de vida.

Traços de negatividade também compõem os discursos das educadoras, especificamente nas narrativas, quando descrevem condições do passado que se transformam no presente (eu não gostava de ler; eu não tinha o hábito). O passado apreciado de modo negativo, marcado pelo déficit, serve para dar relevo e atestar a nova condição alcançada ao final de suas narrativas: um presente pleno e positivo (agora en leio; eи leio até o fim, eu gosto muito de poesias). Esses traços de negatividade presentes nas descrições iniciais em seus relatos não se colocam como impeditivos à superação das condições desfavoráveis e não põem em dúvida a capacidade de enfrentá-los; funcionam para representar as condições com as quais não querem mais se identificar (pessoas que não gostavam de ler e que não tinham o hábito, que não liam um livro até o final, por exemplo).

Os alfabetizadores-participantes dessa roda de conversa encontravam-se em posições de sujeito variáveis, como a de educadores que atuam na alfabetização de pessoas jovens e adultas na educação não formal; a de educadores que pretendem aprimorar e aprender novas práticas e, centralmente, a de participantes reconhecidos cujas histórias de vida e posicionamento sobre a leitura e leitores interessavam. Faziam parte de um projeto educativo que pretendia intervir na realidade local, o que os colocava em posição de sujeitos solidários com pessoas que, no jogo social, estão em situação de desvantagem frente a eles. São alçados à

VÓVIO - Construções identitárias... 
posição de agentes sociais cuja função é alfabetizar jovens e adultos e, com isso, promover mudanças na vida dessas pessoas. Essa posição de sujeito pareceu exercer influência no modo como produziram imagens de si. Diferentemente dos professores cuja posição lhes é outorgada por meio de certificação, estatuto profissional e local de atuação, esses educadores tendem a construir sua identidade profissional na ação cotidiana e nos processos formativos em serviço, num lócus improvisado, que depende de sua proatividade, tanto para criar condições de infra-estrutura (espaço, materiais, equipamentos, mobiliário) como para organizar as turmas de alfabetização e mantê-las.

\section{CONSIDERAÇÕES FINAIS}

Objetivar-se como leitor ou conceber-se como um leitor-tipo exigiu dos alfabetizadores-participantes reunirem um conjunto de traços e características (atributos e propriedades) que estabelecem fronteiras entre nós e eles e constroem pontes com os outros (com os quais se identificam), com comunidades que se deseja instaurar ou das quais se deseja participar (WOODWARD, 2000). Esses enunciados se referem tanto ao pertencimento a um determinado grupo (daqueles que dizem e valoram certas práticas, que as realizam de modos situados, com pessoas e com determinados objetos e instrumentos culturais), como à credibilidade do pertencimento declarado (a plausibilidade daquilo que dizem e afirmam ser). Expressam, portanto, a avaliação apreciativa e o posicionamento dos sujeitos diante dos objetos de seu discurso ${ }^{10} \mathrm{e}$ diante das posições de outros que influem no seu dizer. Também lhes permite construir uma rede social que funciona como lócus de reposição identitária, para efetivar mudanças e transformações. Seus auto-retratos e o modo como os enunciam oferecem uma visão desses alfabetizadores como tributários de práticas culturais hegemônicas e, ao mesmo tempo,

\footnotetext{
${ }^{10}$ Em Bakhtin [Volochínov] (1981), enunciar é tomar uma posição avaliativa, é replicar, é assumir um posicionamento frente a outros tantos, é "apenas uma fração de uma corrente de comunicação verbal ininterrupta" (p. 123). Os enunciados dos alfabetizadores-participantes foram tomados como situados e singulares, constituídos pelos discursos já-ditos e por aqueles que emergiram no interior de e a partir da situação.
} 
como tomando parte nesse domínio e agindo em favor de si mesmos, transformando-os e deslocando-os a contextos culturais diferentes daqueles de seus grupos de origem.

A ênfase na posição de leitores tem como efeito enunciar uma movimentação cultural que se opera entre os interstícios da cultura dominante e das outras produções culturais, incluindo-se as de seus grupos de origem, nas diversas esferas sociais de que tomam parte. Sua trajetória e modos como se representam atestam conquistas; mostramnas engajadas na superação de dificuldades, colocando em suspeição fatores sociais e econômicos tomados como condicionantes de suas experiências com e entre leituras. Em especial, nas narrativas figuram sujeitos que não perpetuam as condições sociais, mas fazem escolhas dentro das fronteiras da legitimidade que conhecem. Nessa situação, apresentarem-se como leitores ativos e competentes implica mostraremse como capazes de ensinar outras pessoas a ler, de aprimorar práticas de ensino, de propiciar aos seus estudantes o desenvolvimento de competências, hábitos e gosto pela leitura. Suas imagens atestam a legitimação não só como leitores, mas também como educadores.

\section{REFERÊNCIAS}

ABREU, M. Diferença e desigualdade: preconceitos em leitura. In: MARINHO, M. (Org.). Ler e navegar: espaços e percursos da leitura. Campinas: ALB; CEALE; Mercado de Letras, 2001. p. 139-157.

AMOSSY, R. Da noção retórica de ethos à análise do discurso. In: AMOSSY, R. (Org.). Imagens de si no discurso: a construção do ethos. São Paulo: Contexto, 2005. p. 9-28.

BAKHTIN, M. [VOLOCHÍNOV]. Marxismo e filosofia da linguagem. São Paulo: Hucitec, 1981.

Questões de literatura e de estética: a teoria do romance. São Paulo: Unesp; Hucitec, 1993.

Estética da criação verbal. São Paulo: Martins Fontes, 2003.

CHARTIER, R. Formas e sentido da cultura escrita: entre distinção e apropriação. Campinas: ALB; Mercado de Letras, 2003.

VÓVIO - Construções identitárias... 
CUCHE, D. A noção de cultura nas ciências sociais. Bauru: EDUSC, 2002. DE CERTEAU, M. A invenção do cotidiano: artes de fazer. Petrópolis: Vozes, 1994.

GALVÃO, A. M. O.; BATISTA, A. (Orgs.). Leitura: práticas, impressos, letramentos. Belo Horizonte: CEALE; Autêntica, 1999.

GOODY, J. Language and writing. In: The interface between the written and the oral. Cambridge: Cambridge University Press, 1987. p. 258259.

GRAFF, H. J. O mito do alfabetismo. Teoria \& Educação, Porto Alegre, n. 2, p. 31-63, 1990.

HÉBRARD, J. O autodidatismo exemplar: como Valentin Jamerey-Duval aprendeu a ler? In: CHARTIER, R. (Org.). Práticas da leitura. São Paulo: Estação Liberdade, 2001. p. 35-73.

KLEIMAN, A. B. (Org.). Os significados do letramento: uma nova perspectiva sobre a prática social da escrita. Campinas: Mercado das Letras, 1995.

Programas de educação de jovens e adultos e pesquisa acadêmica: a contribuição dos estudos do letramento. Educação e Pesquisa, São Paulo, v. 27, n. 2, p. 267-281, jul./dez. 2001a.

. (Org.). A formação do professor: perspectivas da lingüística aplicada. Campinas: Mercado de Letras, 2001b.

A interface de questões éticas e metodológicas na pesquisa em lingüística aplicada. In: SILVA, D. E.; VIEIRA, J. A. (Orgs.). Análise do discurso: percursos teóricos e metodológicos. Brasília: UNB-Oficina Editorial do Instituto de Letras; Plano, 2002a.

Contribuições teóricas para o desenvolvimento do leitor: teorias de leitura e ensino. In: RÖSING, T. M. K.; BECKER, P. (Orgs.). Leitura e animação cultural: repensando a escola e a biblioteca. Passo Fundo: UPF, 2002b. p. 49-68

As metáforas conceituais na educação lingüística do professor: índices da transformação de saberes na interação. In: KLEIMAN, A.; MATENCIO, M. L. M. (Orgs.). Letramento e formação do professor: práticas discursivas, representações e construção do saber. Campinas: Mercado de Letras, 2005. p. 203-228. 
. Professores e agentes de letramento: identidade e posicionamento social. Revista Filologia e Lingüística Portuguesa, São Paulo, n. 8, p. 409424, 2006.

LAHIRE, B. Homem plural: os determinantes da ação. Petrópolis: Vozes, 2002.

A cultura dos indivíduos. Porto Alegre: Artmed, 2006.

MAINGUENEAU, D. Ethos, cenografia, incorporação. In: AMOSSY, R. (Org.). Imagens de si no discurso: a construção do ethos. São Paulo: Contexto, 2005. p. 69-90.

OLIVEIRA, M. K.; VÓVIO, C. L. Homogeneidade e heterogeneidade nas configurações do alfabetismo. In: RIBEIRO, V. M. M. (Org.). Letramento no Brasil: reflexões a partir do INAF. São Paulo: Global, 2003. p. 155-175.

OLSON, D. R.; TORRANCE, N. Cultura escrita e oralidade. São Paulo: Ática, 1995.

RIBEIRO, V. M. M. Alfabetismo e atitudes: pesquisa junto a jovens e adultos. São Paulo: Ação Educativa; Campinas: Papirus, 1999.

- Uma perspectiva para o estudo do letramento: lições de um projeto em curso. In: KLEIMAN, A.; MATENCIO, M. de L. M. (Orgs.). Letramento e formação do professor: práticas discursivas, representações e construção do saber. Campinas: Mercado de Letras, 2005. p. 17-40.

ROSA, E. C. S. A leitura na vida de professoras: relatos, práticas e formação docente. Tese (Doutorado em Psicologia) - Universidade de São Paulo, 2003.

STREET, B. Literacy in theory and practice. Cambridge: Cambridge University Press, 1984.

. Los nuevos estudios de literacidad. In: ZAVALA, V.; MURCIANINO, M.; AMES, P. (Orgs.). Escritura y sociedad: nuevas perspectivas teóricas y etnográficas. Lima: Red para el Desarrollo de las Ciencias Sociales en el Peru, 2004. p. 143-180.

TARDELLI, G. Histórias de leitura de professores: a convivência entre diferentes cânones de leitura. Tese (Doutorado em Lingüística Aplicada) Universidade Estadual de Campinas, Instituto de Estudos da Linguagem, 2003.

VÓVIO, C. L. Entre discursos: sentidos, práticas e identidades leitoras de alfabetizadores de jovens e adultos. Tese (Doutorado em Lingüística Aplicada) Instituto de Estudos da Linguagem, Universidade Estadual de Campinas, 2007.

VÓVIO - Construções identitárias... 
; SOUZA, A. L. S. Desafios metodológicos em pesquisas sobre

letramento. In: KLEIMAN, A.; MATENCIO, M de L. M. (Orgs.). Letramento e formação do professor: práticas discursivas, representações e construção do saber. Campinas: Mercado de Letras, 2005. p. 41-64.

WOODWARD, K. Identidade e diferença: uma introdução teórica e conceitual. In: SILVA, T. T. Identidade e diferença: a perspectiva dos estudos culturais. Petrópolis: Vozes, 2000. p. 7-72.

Recebido em 16/08/08. Aprovado em 23/09/08.

Title: Identity construction: being a reader and a literacy trainer of young people and adults

Author: Claudia Lemos Vóvio

Abstract: This article focuses on the relations between language and the construction of reading identities by non-formally trained teachers of adults and young adults in basic literacy programs. Results from a $\mathrm{PhD}$ research focusing on the study of these agents' literacy process are presented. We asked the subjects what type of readers they were, in order to learn the meanings they attributed to reading, with the purpose of contributing to programs geared to their professionalizing and community needs. The data analysis, from a linguistic-enunciative and discursive perspective, revealed differences from previous research results involving professionally trained literacy teachers, i.e., the assertive and positive ways in which the subjects produced their selfimages as readers and, consequently, as literacy teachers. We observed a selflegitimation movement through discursive operations which focus on the exaltation of personal characteristics, on the reference to cultural objects taken as legitimate, and on the familiarity with new cultural practices.

Keywords: identity; literacy; reading practice; teacher education.

Titre: Des constructions identitaires: être lecteur et instituteur de littératie de jeunes et adultes

Auteur: Claudia Lemos Vóvio

Résumé: Cet article focalise les rapports entre langage et construction d'identités lectrices par des personnes qui se chargent de la littératie des jeunes et des adultes. Il présente des résultats d'une recherche de doctorat qui a eu comme point focal les littératies de ces agents. En interpellant les discours de ces agents à propos d'euxmêmes et en accédant aux sens atribués à la lecture, on a l'intention de contribuer pour la délinéation de procès de formation. L'analyse, dans une perspective linguisticoénonciative-discursive, a révélé un aspect distinct devant les résultats de recherches préalables avec des professionnels enseignants: la forme assertive et positive avec laquelle ils ont produit des images d'eux-mêmes, commme lecteurs et, par conséquent, comme des personnes qui alphabétisent. Dans cette construction, on observe encore un mouvement d'auto-légitimation par le moyen d'opérations discursives qui ont 
comme point focal l'exaltation de propriétés personnelles, la référence aux objets culturels pris comme légitimes et le passage aux nouvelles pratiques culturelles.

Mots-clés: identité; littératie; pratique de lecture; formation des professeurs; littératie de jeunes et adultes.

Título: Construcciones de identidad: ser lector y instructor de literacia a jóvenes y adultos

Autor: Claudia Lemos Vóvio

Resumen: Este artículo focaliza las relaciones entre lenguaje y construcción de identidades lectoras por alfabetizadores de jóvenes y adultos. Presenta resultados de una investigación de doctorado que tuvo como foco las literacias de esos agentes. Al interpelar los discursos de esos agentes sobre sí mismos y acceder a los sentidos atribuidos a la lectura, se pretende contribuir para el delineamento de procesos de formación. El análisis, en una perspectiva lingüístico-enunciativo-discursiva, reveló un aspecto distintivo frente a los resultados de pesquisas previas con profesionales docentes: la forma asertiva y positivada con que produjeron imágenes de sí, como lectores y, consecuentemente, como alfabetizadores. En esa construcción, se observa aún un movimiento de auto-legitimación por medio de operaciones discursivas que tienen como foco la exaltación de propiedades personales, la referencia a objetos culturales tomados como legítimos y el tránsito por nuevas prácticas culturales.

Palabras-clave: identidad; literacia; prácticas de lectura; formación de profesores; alfabetización de jóvenes y adultos.

VÓVIO - Construções identitárias... 